\title{
Health-care Providers' Perceptions, Attitudes toward, and Recommendation Practice of Cervical Cancer Screening
}

\author{
Nada Ab. Hweissa’ Jennifer NW Lim· Tin Tin Su
}

Nada Ab. Hweissa

Department of Social and Preventive Medicine, Faculty of Medicine, University of Malaya, Kuala Lumpur, Malaysia. Email: hawisa84@yahoo.com

Jennifer NW Lim

Department of Allied and Public Health, Faculty of Medical Science, Anglia Ruskin University, Cambridge, United Kingdom. Email: jennifer.lim@anglia.ac.uk

Tin Tin Su

Head, Centre for Population Health, Department of Social and Preventive Medicine, Faculty of Medicine, University of Malaya, Kuala Lumpur, Malaysia. Email: tintinsu@um.edu.my 


\begin{abstract}
Cervical cancer is still the cause of morbidity and mortality worldwide; it ranks as the fourth most common cancer in women worldwide. Early diagnosis has been shown to reduce morbidity and mortality due to cervical cancer. Although health-care providers can influence women's screening behaviours, their lack of recommendations for the test becomes one barrier that affects the women's participation in the screening programmes. This study aims to assess the health-care providers' perception, attitude toward and recommendation practice of cervical cancer screening. Sixteen in-depth interviews were conducted face to face with health-care providers, from both public and private sectors in Az-Zawiya city since February until July 2014. The interviews were recorded, transcribed, and then analysed using thematic analysis. The findings of this study highlight the importance of women's motivation to attend cervical cancer screening programs. It also expressed a need for implementation of reminding system. On the other hand, this study showed the shortage amongst health care providers in advising and giving enough information regarding cervical cancer screening. In addition, Health care providers stated the necessity for educational and awareness campaigns of cervical cancer screening among Libyan women. Also appeared is the need to improve health education by the health-care providers.
\end{abstract}

Keywords: Health care providers, cervical cancer, perceptions, attitudes, recommendation Practice, Libya. 


\section{Introduction}

Cervical cancer is still the cause of morbidity and mortality despite the success of cervical cancer screening programmes and HPV immunisation programmes (Queensland Cervical Screening Program, 2009). It is the fourth most common cancer in women worldwide, with an estimated 528,000 new cases and 266,000 deaths in 2012 (Jacques Ferlay et al., 2015). In Libya, cervical cancer is ranked third as the most frequent cancer among women and seventh among women aged between fifteen and forty-four (Institut Català d'Oncologia, 2014). Annually 241 new cervical cancer cases are diagnosed with estimated 95 deaths registered every year (Bruni L et al., 2015).

Prevention, early diagnosis and treatment have been shown to reduce mortality due to cervical cancer. Since 1940s, the Pap smear test has been effective in detecting cervical cancer (GN, 1948). The test can detect any abnormalities of the cervix at an early stage and medical intervention can avoid the possible progression to cervical cancer (Queensland Cervical Screening Program, 2009). In Libya, the Pap smear test is available in some of the general hospitals and a number of private clinics, although the screening uptake in most of Middle East and Arabic countries is still low. This is related to the low level of awareness of cervical cancer screening in these countries (Khadija El-Hammasi and Athari Al-Fadli, 2009).

While organised cervical cancer screening programmes have been introduced in most developed and developing countries, none exists in the Middle East or Arabic countries (Khadija El-Hammasi and Athari Al-Fadli, 2009). The developed countries have established regular screening for eligible women, and this have reduced mortality cases from invasive cervical cancer (Peter Barton-Smith et al., 2003, Sankaranarayanan et al., 2001). In Iceland, Finland, Sweden, and Denmark, the implementation of organised, population-based cervical 
screening programmes has significantly reduced cervical cancer mortality (International Agency for Research on Cancer, 1986).

Health care providers play a key role in cervical cancer control by informing women to seek medical attention for abnormal vaginal bleeding and other clinical symptoms (BC Cancer Agency, 2013). Lack of recommendation by health-care providers has prevented women from taking the Pap smear test (Wong L P et al., 2009). Health-care providers can influence women's screening behaviours (Wong L P et al., 2009) and increase their confidence in cervical cancer screening by helping them understand the importance of regular screening and the benefits of the Pap smear test. It is also important for the health-care providers to inform the women that any symptoms such as bleeding, discharge, or pain between the Pap smear tests may require investigation even if the previous result is normal (Queensland Cervical Screening Program, 2009).

Healthcare providers play an important role in getting patients screened for cancer; they should discuss with women the balance between the potential benefits and harms of screening with Pap tests. This is to help the women make informed decision about screening which is consistent with their values and preferences (Canadian Task Force on Preventive Health Care, 2013). This qualitative study was conducted to identify the provider's attitude toward and recommendation practice of cervical cancer screening among women in Az-Zawiya City, Libya.

\section{Methods}

Qualitative in-depth interviews were conducted with health-care providers from public and private sectors in Az-Zawiya City between February to July 2014 to assess their attitude and practice of cervical cancer screening. A semi-structured interview guideline was developed, beginning with the researcher introducing herself and informing the reasons for the interview. 
The researcher then sought the participants' perceptions, attitudes, and recommendation practices on cervical cancer screening.

For a qualitative study, a large sample size is not as important as the depth and details of data obtainable by the researcher (Sandelowski, 1995). For the face-to-face interviews, sixteen informants were selected by purposive sampling; eight were specialists in gynaecology and eight were general practitioners.

In Az-Zawiya city, there are two main hospitals with total of 616 beds, three in-patient clinics with capacity of 82 beds and 32 outpatient clinics (World Health Organization, 2007). Regrettably, the two public hospitals lack for cervical cancer screening and usually transfer women with warning signs or symptoms of cervical cancer to Sabratha oncology centre which lies $25 \mathrm{~km}$ away from the city centre. On the other hand, there was only one inpatient clinic and two outpatient clinics provide Pap smear test service and women had to pay 50 USD to get it.

In the first public hospital there were 6 gynaecologists and 29 general practitioners. The other hospital had 5 gynaecologists and 32 general practitioners . Through the heads of departments, one gynaecologist and another general practitioner were approached from each hospital to participate in the study. In the polyclinics, in-patient clinics and out-patient clinics, gynaecologists and general practitioners usually range from one to four. The study was approached two gynaecologists and two general practitioners from each of them. All participants from both public and private sector were very cooperative and none of targeted doctors declined to participate in the study

The interviews were conducted in Arabic and were later translated to English for analysis. The duration of each interview was about 40 minutes. The researcher was organized the time and place of interview with each participant. Most of interviews were conducted in 
participant's workplace as they proposed and only three were at participant's home. To get greater conversation and more detailed information, the interviews were carried out in closed offices or rooms at the chosen place. All conversations were tape-recorded with permission and the field notes were taken at the same time of recording.

Thematic analysis is the most commonly used method of analysis in a qualitative research, and it is used to capture the complexities of meaning within the textual data set (Gery W. Ryan and Bernard, 2000). Once completed, the interviews were transcribed verbatim to yield the textual data. These data were then checked with the field notes for consistency. Codes were developed to serve as labels for sections of the data. The coding procedure included two steps: the basic coding where data description was done, and the axial coding which included conceptual ordering.

Ethics approval was obtained from University Malaya Medical Centre (UMMC) Ethics Committee under reference number 982.15. A written informed consent was obtained from all the study participants, in addition to verbal permissions to allow audio recording of the interview.

\section{Results}

The participants consisted of fourteen females and two males from the public and private sectors. Those healthcare providers were with seven and more years of working experience at the time of interview. Figure 1 shows the sampling procedure used for selecting the healthcare providers. In general, not much difference was noted in the comments made by the health-care providers from the public or private sector, or from the specialists or general practitioners. The findings of this study explain the healthcare providers' attitude, recommendation practices, and perceptions regarding cervical cancer screening.

\section{Health-care Providers' Attitude toward Cervical Cancer Screening}


In general, the interviews showed a shortage among health-care providers in both sectors in providing enough information about cervical cancer screening for their patients. The compliance for cervical cancer screening among women will be low as a result of lack of information about the Pap test.

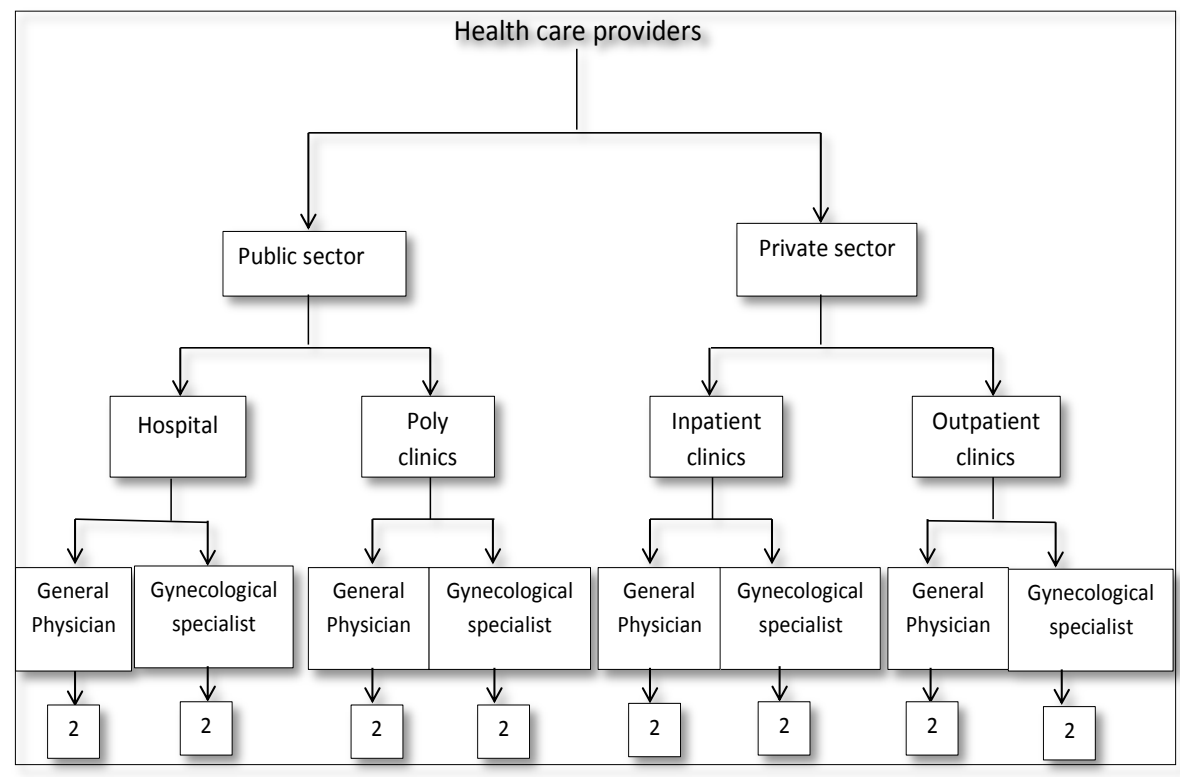

Figure 1 Purposive sampling Diagram of key informants

\section{Explanation by Health-care Providers on the Pap Smear Test}

None of the participants reported that they explain to healthy women about cervical cancer screening. They only explain about the test to women who are suspected or symptomatic of cervical cancer, and they may also give information about the screening test to patients aged thirty and above. Participants clarified that they describe the nature of Pap smear test and simplify that the test is only a screening test for cancerous cells in early time, and how is the detection of the abnormal cells effective in saving the women's lives. As a result, giving information about cervical cancer screening and explanation about its procedure is only restricted to symptomatic and elder women. Consequently, those who are young and healthy may never get information from the health-care providers. 
"I usually ask patients at risk, like those who have signs and symptoms of cervical cancer. As well as, those who are more than 30 years old, because this age regards as one of cervical cancer risk factors" (Female GP, 9 years work experience at polyclinic)

\section{Compliance for Cervical Cancer Screening Test}

Seven participants, five from public hospital and two from private clinics, indicated that healthy women may agree to undertake a cervical cancer screening test if they get sufficient information about it. The other three participants from public sector and one from inpatient clinic mentioned that women do not go for a screening test without having any warning signs or symptoms. The health-care providers also clarified that the attendance for regular cervical cancer screening depends on many factors varying from one woman to another, and the factors are the women's awareness of cervical cancer screening, education level, age, health status, family history, and economic situation.

"The acceptance of doing regular Pap smear depends on woman herself, her education level and economic status. For example; educated women tend to accept to do screening more than uneducated. In addition, those who have symptoms or family history of cervical cancer usually accept and do the test directly. Particularly, when I explain to them that the test will protect your life". (Female GP, 12 years of work experience at inpatient clinic)

\section{Barriers Affecting Women's Participation in Regular Cervical Screening}

Several barriers that may hinder women's participation in cervical cancer screening were identified through this study and were classified as follows:

1. Health-care provider-related barriers: These barriers include the obstacles that prevented the health-care providers from explaining or inviting women for cervical cancer screening, which are: 
a. Limited time for consultation: Two specialists from private clinics and two general practitioners from public sector mentioned that they lack the time to discuss with every patient about cervical cancer screening. They attend to a large number of patients thus restricting their duration of consultations.

\section{"I am working in public hospital and usually there is large number of patients every day. So, it is difficult to explain for each patient as a result of limited time”. (Female specialist, 7 years of work experience at polyclinic)}

b. Gender of health care provider: Two male participants indicated that the gender of health-care provider affects women's acceptance to do the Pap smear test:

Because I am male doctor, many women feel uncomfortable to talk about pelvic examinations. So, they always prefer to go for female doctor. And fortunately, in our city, female gynaecologists are much more than males. (Male GP, 9 years of work experience at public hospital)

2. Health System related barriers: The most prevalent system barriers to cervical cancer screening reported among the study were:

a. Accessibility of the Screening Test: Majority of participated health-care providers mentioned that Pap smear test is not available in the public sector except in Sabratha Oncology Centre. This centre provides the service only for women who have signs of cervical cancer and were being referred from other hospitals or clinics. Women with no symptoms may not get a chance for screening in this oncology centre. Moreover, this centre is located far away and women need to travel long distance to access the service. Additionally, in the private sector, only some clinics provide cervical cancer screening service. The cost for a Pap smear test is high; it costs USD50, thus women may refuse to take the test. 
"When I ask the patient to go for such a screening, I should refer her to the place in which she does the test. And because Sabratha cancer centre regards quit far from Az-Zawiyah city, that may cause problem for some women on how to go there. On the other hand, when I refer her to private clinic, first thing she will ask about is the PRICE of Pap smear test. And in this case, she may refuse to go because of high cost of the test,...especially if she doesn't have any signs or symptoms of cervical cancer". (Female GP, 18 years of work experience at public hospital)

b. The cost of screening test: Participants clarified that cervical cancer screening is not provided in public sector and women have to pay for the test in the private sector. In addition, most women consider that USD50 is unreasonable when they are not having any warning signs of cervical cancer.

Sometimes I ask some women for blood test which costs not more than 10 dollars; they may not come back with the result. (Female GP, 8 years of work experience at polyclinic)

3. Consumer-related barriers: The participants mentioned number of barriers that hinder a woman from attending the screening programme. At most they perceived that low level of awareness among Libyan women is the main reason and that women often refuse to do the test because they don't have any signs or symptoms.

A need of husband's approval and support of doing cervical cancer screening test was also mentioned as a barrier to a screening procedure, as stated by seven participants from both the public and the private sector.

From my experience, I saw some husbands who never care about their wives. And they may not prefer to pay for a screening test without any symptoms. Financial assistance by husbands is regarded as the main factor for women to 
participate in the screening programme. (Female specialist, 13 years of work experience at outpatient clinic)

For some women, shyness, neglect, lack of time, fear of knowing the test result, and accessibility to the test are the barriers to do the screening test as mentioned by some of the interview participants.

\section{The Health-care Providers' Perceptions Regarding Cervical Cancer Screening}

The health-care providers expressed their worrying about women's awareness as well as limited health system service of cervical cancer screening, and they highlighted some suggestions to improve cervical cancer screening in Libya, in terms of motivation of women to attend regular cervical cancer screening, implementation of reminding system, and their opinion to the current costs of the Pap smear test.

\section{Motivation for Women to attend Regular Cervical Cancer Screening}

According to the participants, what motivate women are time, money, and power. Hence they proposed the following ways to motivate women and increase their attendance for regular cervical cancer screening:

\section{a. Educational and Awareness Campaigns}

Most of the participants explained about the importance of educational and awareness campaigns to increase women's awareness of cervical cancer warning signs and risk factors, as well as early detection of cervical cancer through regular screening. A female specialist from an inpatient clinic said:

Since 4 years ago, there has been a breast cancer awareness campaign performed through one month in year among all secondary schools in Libya. This campaign has improved the women's awareness of breast cancer. And because of these campaigns we received many patients intended for early diagnosis of breast cancer and consequently we could discover a number of cases in early stages. So, these 
awareness campaigns will improve women's awareness of cervical cancer and will increase their attendance for Pap smear test. (Female specialist, 8 years of work experience at inpatient clinic)

\section{b. Media, Posters, and Leaflets}

The health-care providers also mentioned about the significance of media in increasing woman's motivation to attend regular screening. Posters and leaflets can explain about cervical cancer warning signs and risk factors, and the importance of detecting the disease early to save a woman's life, and this form of media can be distributed in schools, universities, clinics and hospitals.

Information dissemination through posters and leaflets in public places may draw the attention of women. These posters should highlight cervical cancer risk factors, warning signs and the importance of early screening. (Female GP, 12 years of work experience at inpatient clinic)

\section{c. Offering a Free Pap Smear Test}

Five participants from both public and private sectors stated that offering the Pap test free-of-charge may increase women's attendance for screening. Woman usually will not pay for such a costly service without having any symptoms thus a free screening in the public sector will motivate them to do the test regularly.

Pap smear is not available in public sector. Usually, when I ask women to do the Pap test, they need to go to the private sector and in this case, they may not accept because of financial issues. But if the service is provided in public sector as free, women's attendance will be increased. (Male GP, 9 years of work experience at public hospital)

\section{Reminding Women to do Regular Screening}


Most participants indicated that reminding the women to do a regular Pap smear test after three years is not easy. Hence implementing the reminding system requires a good planning, time, and efforts, and this was regarded as one of the main roles of the Ministry of Health.

\section{a. Implementation of Proper Reminding System}

Seven health-care providers mentioned about the importance of implementing of a callrecall system such as the one available in developed countries, while the other five participants from both sectors highlighted the difficulty of implementing such a programme in this time because of limited current resources. Some indicated that awareness campaigns with doctors' encouragement will improve the women's attendance for screening programmes. A female specialist at an outpatient clinic proposed compulsory attendance for a screening programme:

We can do,,, that the attendance for Pap smear screening is compulsory. And small booklets can be given as a reminder, and those who don't come for their next screening date have to pay fine. In this case we may get 100\% Pap smear screening. (Female GP, 12 years of work experience at outpatient clinic)

\section{b. Attendance without Reminding}

The health-care providers were asked women's attendance without encouragement and reminding. Fourteen participants answered, "No", or that the women would never attend. The other two participants highlighted that women's awareness of cervical cancer screening plays an important role in their attendance without reminding.

“Women's attendance without reminding depends on women's awareness of cervical cancer screening. Most of Libyan women have no idea about Pap smear test, but if they get adequate information and the test be obtainable, then their attendance will be 
improved and they may come without reminding". (Male specialist, 20 years of work experience at public hospital)

\section{Health-Care Providers' Opinion of the Cost of Pap Smear Test}

Half of the participants indicated that fifty dollars is not expensive to be paid every three years. They explained that this amount will be paid to detect any abnormal cells in the cervix, and then woman's life can be saved rather discovering cervical cancer at later stages.

Fifty dollars is not expensive at all and woman will pay it once every three years.... And by this amount she may avoid payment of thousands of dollars to cure from cervical cancer lesions in future. (Female specialist, 16 years of work experience at public hospital)

Other participants perceived that the amount of fifty dollars is expensive to pay for a screening test. As a result of the low level of awareness of screening test among women, they may not prefer to pay without any warning signs appeared.

In addition, some of interviewees expressed that the cost of a Pap smear test depends on the woman herself. It depends on her level of awareness and education, socio-economic status and her family history. Educated women aware of the screening test, women with high socioeconomic status, and those who have family background of cervical cancer may accept to pay for cervical cancer screening test.

\section{Discussion}

Health-care provider plays a crucial role in educating women about the benefits of cervical cancer screening and the importance of regular a Pap smear test (BC Cancer Agency, 2013, L. P.Wong et al., 2008). Encouragement and motivation from doctors appeared to be an important factor in assuring that the women would attend for a Pap smear test (Taylor VM et al., 2002, Tung T. Nguyen et al., 2002, Anisah Baharom and Ismail., 2008). Apparently the health-care providers in Az-Zawiya city do not explain about a Pap smear test for their 
asymptomatic patients. An earlier qualitative study performed among Malaysian women confirmed that they have never been informed of the existence and importance of a Pap smear test by health-care professionals (Wong L P et al., 2009).

The study indicated a shortage of health-care providers in giving information about cervical cancer screening for their patients. Providing information and recommendation of health professionals are only restricted to elderly women and those who have warning signs or symptoms of cervical cancer. However, a study performed in 2009 among Vietnamese immigrants in Seattle, Washington to demonstrate the importance of health care factors highlighted the significance of intervention programmes to improve patient-provider communication, particularly by encouraging health-care providers to recommend Pap smear testing (Taylor et al., 2009).

The commonest weakness of cervical cancer screening mentioned in the interviews was the accessibility of Pap smear test. According to the Ministry of Health in Az-Zawiya city, Pap smear test is available in one public hospital which is Sabratha Oncology Hospital. This hospital provides the service as free of fees, but the test is only applicable for patients who have been transferred from other hospitals and clinics. Therefore, women who plan to do cervical cancer screening have to go to the private sector and pay for the test. Consequently, accessing the service from a particular location may be difficult for women as demonstrated by previous studies (Queensland Cervical Screening Program, 2009, Marion Maar et al., 2013).

Some of health-care providers stated that the frequent refusal of cervical cancer screening among their asymptomatic patients have made them unwilling to spend time to explain about the Pap smear test. A qualitative study performed in 2010 found that all participants admitted poor women's acceptability to cervical cancer screening programme (Abdullah and Su, 2010). Hence unacceptability and frequent refusal of women to participate in cervical cancer 
screening programme have discouraged the health-care providers in giving advice and support to asymptomatic women.

The health-care providers highlighted a few barriers that prevent women from performing a regular Pap smear test. Low level of awareness about screening test was the main factor; women lack adequate knowledge about the importance of a Pap smear test. A study performed among Malaysian women in 2009 found that women were poorly aware of the indications and benefits of cervical cancer screening and they were not aware that a Pap smear test is for the early detection of cervical cancer (Wong L P et al., 2009).

Participated health-care providers were underlined some other barriers of cervical cancer screening, and that has emphasized the findings of previous studies. For example, Participants mentioned about the financial factor which is significantly affect women's participation in cervical cancer screening. This was confirmed previously through the case studies on decision for cervical cancer screening which underlined that woman will only have her Pap smear done if she has extra money (Anisah Baharom and Ismail., 2008). Moreover, the gender of health care provider may affect women's acceptance of doing a Pap smear test (Queensland Cervical Screening Program, 2009, Nseem Mohamed Bakheit and Haroon, 2004). A study performed in Emirates concluded that in most traditional Islamic societies, female genital examination by a male is culturally unacceptable except in extraordinary circumstances in secondary care (Padmanabhan Badrinath et al., 2010, Nseem Mohamed Bakheit and Haroon, 2004). The health-care providers in this study indicated the importance of husband's approval and support to do a Pap smear test. A case study performed in Malaysia highlighted the role of husband in encouraging women to practice preventive health care (Anisah Baharom and Ismail., 2008).

This study has stressed the importance of educational and awareness campaigns to improve women's attendance for cervical cancer screening programmes. Improving education and 
information dissemination about a Pap smear test through awareness campaigns will increase their awareness of cervical cancer screening (Jugal Kishore et al., 2009, Forough Javanmanesh et al., 2008).

In developed countries, the implementation of call-recall organized cervical cancer screening programmes resulted in reduced morbidity and mortality of cervical cancer (Abdullah and $\mathrm{Su}$, 2010, Peter Barton-Smith et al., 2003). Most participants in this study mentioned the difficulty of reminding women every three years to practice a regular Pap smear test, and these interviewees stressed the importance of implementing a call-recall system to ensure success in increasing Pap smear test coverage.

In conclusion, the finding of this study indicated that there is a need to improve patientprovider relationship. In addition to, enhancement of health system services to ensure comprehensive cervical cancer screening coverage. Lack of physician's recommendation was found to be one of the reasons of low Pap smear test coverage (L. P.Wong et al., 2008). Suggestion should be made to the authorities to have to improve health education by healthcare providers. In addition, more information on cervical cancer and its screening should be disseminated especially in electronic media as well as in educational and awareness campaigns. There is also a promising possibility to increase the cervical cancer screening rate by implementing low cost or free organized population based screening programme. 


\section{References}

ABDULLAH, F. \& SU, T. T. 2010. Enhancement of the Cervical Cancer Screening Program in Malaysia: A Qualitative Study. Asian Pacific J Cancer Prev, 11, 1359-1366.

ANISAH BAHAROM \& ISMAIL., M. 2008. Case Studies on Decision for Cervical Cancer Screening among Working Women. The Journal of Human Resource and Adult Learning, 4, 173-184.

BC CANCER AGENCY 2013. Screening for Cancer of the Cervix.

BRUNI L, BARRIONUEVO-ROSAS L, ALBERO G, ALDEA M, SERRANO B, VALENCIA S, BROTONS M, MENA M, COSANO R, MUÑOZ J, BOSCH FX, DE SANJOSÉ S \& X., C. 2015. Human Papillomavirus and Related Diseases in Libya. Summary Report 2015-03-20. ICO Information Centre on HPV and Cancer (HPV Information Centre).

CANADIAN TASK FORCE ON PREVENTIVE HEALTH CARE 2013. Recommendations on screening for cervical cancer. CMAJ, 185.

FOROUGH JAVANMANESH, FARIDEH DADKHAH \& ZAREPOUR, N. 2008. Knowledge and awareness among Iranian women regarding the pap smear. Medical Journal of the Islamic Republic of Iran., 22, 68-73.

GERY W. RYAN \& BERNARD, H. R. 2000. Data management and analysis methods. Handbook of qualitative research.

GN, P. 1948. A survey of the actualities and potentialities of exfoliative cytology in cancer diagnosis. Ann Med, 30, 661-74.

INSTITUT CATALÀ D'ONCOLOGIA 2014. Libya, Human Papillomavirus and Related Cancers, Fact Sheet 2014. ICO Information Centre on HPV and Cancer.

INTERNATIONAL AGENCY FOR RESEARCH ON CANCER 1986. Screening for squamous cervical cancer: duration of low risk after negative results of cervical cytology and its implication for screening policies. Br Med J. , 293, 659-664.

JACQUES FERLAY, ISABELLE SOERJOMATARAM, RAJESH DIKSHIT, SULTAN ESER, COLIN MATHERS, MARISE REBELO, DONALD MAXWELL PARKIN, DAVID FORMAN \& BRAY., F. 2015. Cancer incidence and mortality worldwide: Sources, methods and major patterns in GLOBOCAN 2012. International Journal of Cancer, E359-E386.

JUGAL KISHORE, VISHAL MUNDRA \& GREWAL, I. 2009. PERCEPTION AND USE OF PAP SMEAR AMONG MEDICAL PERSONNEL IN NEW DELHI, INDIA. Health and Population: Perspectives and Issues, 32, 141-147.

KHADIJA EL-HAMMASI, M. B., CH.B., OLA SAMIR, M.B., CH.B., SOANIA KETTANEH, M.B., CH.B., \& ATHARI AL-FADLI, M. B., CH.B., AND LUKMAN THALIB, PH.D. 2009. Use of and Attitudes and Knowledge about Pap Smears among Women in Kuwait. Journal of women's health, 18.

L. P.WONG, Y. L.WONG, W. Y. LOW, E. M. KHOO \& SHUIB, R. 2008. Cervical Cancer Screening Attitudes and Beliefs of MalaysianWomen who have Never had a Pap Smear: A Qualitative Study. International Journal of Behavioral Medicine, 15, 289-292.

MARION MAAR, ANN BURCHELL, JULIAN LITTLE, GINA OGILVIE, ALBERTO SEVERINI, JINGHAO MARY YANG, BASC \& INGEBORG ZEHBE 2013. A Qualitative Study of Provider Perspectives of Structural Barriers to Cervical Cancer Screening Among First Nations Women. Womens Health Issues., 23, 319-325.

NSEEM MOHAMED BAKHEIT \& HAROON, A. I. B. 2004. THE KNOWLEDGE, ATTITUDE AND PRACTICE OF PAP SMEAR AMONG LOCAL SCHOOL TEACHERS IN THE SHARJAH DISTRICT. . Middle East Journal of Family Medicine, 4.

PADMANABHAN BADRINATH, SAAD GHAZAL-ASWAD, NAWAL OSMAN, EMAN DEEMAS \& MCILVENNY, S. 2010. A STUDY OF KNOWLEDGE, ATTITUDE, AND PRACTICE OF CERVICAL SCREENING AMONG FEMALE PRIMARY CARE PHYSICIANS IN THE UNITED ARAB EMIRATES. Health Care for Women International, 25.

PETER BARTON-SMITH, VAL THOMAS \& IND, T. 2003. Cervical cancer screening in England and Wales: an update. Reviews in Gynaecological Practice, 3, 5-10. 
QUEENSLAND CERVICAL SCREENING PROGRAM 2009. Handbook for Providers of Medical Practitioner Education.

SANDELOWSKI, M. 1995. Focus on qualitative methods, Sample size in qualitative research. Research in Nursing and Health, 18, 179-183.

SANKARANARAYANAN, R., ATUL MADHUKAR BUDUKH \& RAJKUMAR, R. 2001. Effective screening programmes for cervical cancer in low- and middle-income developing countries. Bulletin of the World Health Organization, 79, 954-962.

TAYLOR VM, JACKSON JC, TU SP, YASUI Y, SCHWARTZ SM, KUNIYUKI A, ACORDA E, LIN K \& G., H. 2002. Cervical cancer screening among Chinese Americans. Cancer Detect Prev. , 26, 139145.

TAYLOR, V. M., YUTAKA YASUI, TUNG T. NGUYEN, ERICA WOODALL, H. HOAI, D., ELIZABETH ACORDA, LIN LI, JOHN CHOE \& JACKSON., C. 2009. PAP SMEAR RECEIPT AMONG VIETNAMESE IMMIGRANTS: THE IMPORTANCE OF HEALTH CARE FACTORS. Ethn Health, 14.

TUNG T. NGUYEN, STEPHEN J. MCPHEE, THOA NGUYEN, TRAM LAM \& MOCK, J. 2002. Predictors of cervical pap smear screening awareness, intention, and receipt among VietnameseAmerican women. Am J Prev Med.,, 23, 207-214.

WONG LP, WONG Y L, LOW W Y, KHOO E M \& R, S. 2009. Knowledge and awareness of cervical cancer and screening among Malaysian women who have never had a Pap smear: a qualitative study. Singapore Med J, 50, 49-53.

WORLD HEALTH ORGANIZATION 2007. Health Systems Profile- Libya. 